$\times 84,8) » y$ «PARIS BORDOGNI / 203. Vénus et l' Amour. / Haut., 2 pieds 4 p.; Larg., 4 pieds 4 p.( traducido a centímetros $74,8 \times 139,6) »{ }^{32}$. Por lo que respecta al primer cuadro, sus medidas no difieren mucho de las del «Apolo entre Marsias y Midas» ( L. $98 \times 81 \mathrm{cms}$ ) que existió en la Gemäldegalerie de Dresde, del que se conoce su procedencia desde el siglo XvIII. Pudiera tratarse de una copia de éste, quizás la «redazione (del cuadro de Dresde, se entiende) più scarsa e forse non autografa» que en 1953 se encontraba en venta en la Galleria G. Cramer de la Haya ${ }^{33}$. En cuanto a la Venus y Cupido, tal vez corresponda al cuadro del mismo asunto conservado actualmente en el Muzeum Narodowe de Varsovia, de medidas muy similares (L. 95 $\times 143$ ) y del que se conoce muy poco sobre su procedencia, o la copia de éste que se conservó o quizás se siga conservando en la colección Engel de Viena ${ }^{34}$. Años después, en la subasta de los cuadros de dicho marqués de 1843 consta: «BORDONE (PARIS), né à Trévise en 1500, mort en 1570. / 267. - Apollon chez les pâtres./ Il est accoudé sur un rocher, dans l'attitude de la méditation et tenant de la main droite une lyre; deux bergers sont vus derrière lui, l'un à droi-

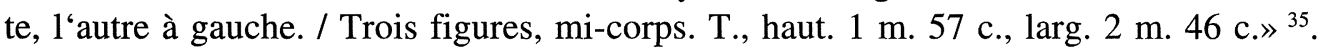

José MARÍA Ruiz MANERo

\title{
UN PROYECTO NO REALIZADO DE FRANCISCO SABATINI PARA EL RETABLO MAYOR EN LA IGLESIA DE SAN CAYETANO DE MADRID
}

La inédita documentación encontrada en el Archivo General de Simancas (A.G.S.), Secretaría y Superintendencia de Hacienda, leg. 943, permite afirmar que Sabatini realizó varias trazas ${ }^{1}$ para levantar el retablo mayor en la iglesia de los Teatinos de Madrid, también conocidos como Clérigos Regulares de San Cayetano. El proyecto no llegó a ejecutarse, si se hubiera realizado constituiría una de las grandes aportaciones de este arquitecto italiano en nuestro país. $^{2}$

La nueva iglesia de San Cayetano se encontraba bajo patronato real, de ahí que tras su finalización arquitectónica en $1761^{3}$, las obras del retablo mayor tuviesen que ser costeadas por Carlos III. El monarca encargó la construcción a su arquitecto de confianza, Francisco Sabatini, que debió realizar varios planos, escogiéndose un único diseño. Se ignora con exactitud

\footnotetext{
${ }^{32}$ Notice des tableaux des écoles espagnoles, italienne, flamande, française et allemande, exposés dans la Galerie du Marquis de las Marismas, París, 1837, pp. 46 y 57.

33 Véase Canova, op. cit., 1963, p. 118.

34 Véase Canova, op. cit., 1963, pp. 114 y 132.

${ }^{35}$ Catalogue des tableaux anciens des Ecoles espagnole, italienne, flamande, .... composant la Galerie de M. Aguado, Marquis de las Marismas dont la vente aux enchères publiques aura lieu par suite de son déces, .... a Paris ...., Paris, 1843, p. 59.

${ }^{1}$ «La Comunidad de Clérigos Regulares de San Cayetano de Madrid (...) hace presente que V.M. tiene mandado hacer varios diseños para construcción del retablo del altar mayor de su yglesia de los que se halla aprobado uno», (A.G.S. Ibid., leg. 943).

${ }^{2}$ Sobre el templo de los Teatinos puede verse el exhaustivo estudio de Matilde Verdú Ruiz, «Intervención de Pedro de Ribera en la iglesia y convento de San Cayetano, en Madrid». Academia. Boletín de la Real Academia de Bellas Artes de San Fernando. Madrid, segundo semestre de 1993, n ${ }^{\circ} 77$, pp. 403-439, recopilando la bibliografía existente hasta ese año (págs. 438-439); de la misma autora puede verse la monografía de Pedro de Ribera. Madrid, Instituto de Estudios Madrileños, 1998. Asimismo y sobre el artista italiano nos remitimos al catálogo de la exposición de Francisco Sabatini, 17211797. La arquitectura como metáfora del poder. Madrid, 1993.

${ }^{3}$ Previamente, el 12 de noviembre de 1755, Manuel López Corona, maestro de obras, informa sobre los reparos que deben ejecutarse en el templo de San Cayetano, tras el terremoto de Lisboa acaecido durante el 1 de noviembre de ese mismo año.
}

AEA, LXXVII, 2004, 306, pp. 171 a 201 
documental en qué fecha se realizaron dichas trazas, aunque debió ser hacia 1761, pues en ese año ya se trajeron algunos mármoles para empezar el proceso constructivo. Un informe del Marqués de Fontanar, encargado de esta empresa artística ${ }^{4}$, confirma, al menos, que la planimetría ya estaba delineada desde antes del 20 de febrero de 1771.

La traza definitiva no aparece dentro de las fuentes manuscritas, eso sí, se nos aclara a través de ellas que el diseño quedó en poder del propio Sabatini. Ignoramos cómo era su alzado, aunque sí conocemos sus materiales, «jaspes, mármoles y bronces»; similar, por tanto, al realizado para la catedral de Segovia. El proyecto quedó aparcado durante una década, retomándose su construcción en 1771, hecho que nunca se produjo. Son varias las razones que justifican que la planimetría quedase en el papel; primera, que todos los esfuerzos económicos de la Corona se concentraban en las obras del nuevo Palacio Real de Madrid, y segunda, que este encargo había quedado interrumpido por los gastos que la Casa Real debía afrontar con motivo de la boda del Príncipe de Asturias, el futuro Carlos IV.

El costo del retablo mayor, según informe de Francisco Sabatini, firmado el 9 de mayo de 1771 (Doc. 1), ascendería a 800.000 reales de vellón, teniendo en cuenta que toda la obra debía ejecutarse en los talleres del Palacio Real, donde se encuentran los instrumentos necesarios para su construcción; herramientas que ya habían sido utilizadas en la realización del altar mayor de la catedral de Segovia.

El 22 de septiembre de 1775, Sabatini solicita al Rey le conceda licencia para construir el retablo de los Teatinos, tras haber finalizado el de la citada catedral, aunque nunca llegó a dispensarse dicho permiso ${ }^{5}$. Éste último dato permite adelantar la fecha de finalización del retablo mayor de la catedral de Segovia, que hasta el momento se databa en el primeros meses de 1776, con un coste total de 620.379 reales, aunque su presupuesto inicial fue de $585.000^{6}$; esas cantidades, si son comparadas con los 800.000 reales del retablo de los Teatinos, nos hacen pensar que este proyecto de Sabatini era mucho más ambicioso que el de la sede catedralicia.

La magnificencia y suntuosidad que podía haber adquirido el presbiterio de San Cayetano con el diseño de Sabatini, quedó reducida a una simple «colgadura y dosel», colocada en 1761 y que tras treinta años se encontraba vieja y bastante indecorosa; así consta en una declaración de don Simón Antonio de Vergara, presbítero de ese convento, que solicita el 14 de julio de 1792 la ejecución del retablo.

La comunidad de Teatinos aporta un listado de los benefactores con los que costearon la construcción de la iglesia, pero no del retablo. Los Clérigos Regulares argumentaban que Felipe V había dado al convento una importante cantidad de 336.000 reales (30.544 ducados), de la que sólo habían percibido una pequeña parte; esa suma fue reclamada constantemente por los religiosos para intentar construir el retablo, aunque nunca llegaron a conseguirlo. En la actualidad, la capilla mayor de la iglesia de San Cayetano está decorada con el antiguo retablo de la parroquia de San Millán, derribada en $1869^{7}$.

Como complemento a lo dicho en estas líneas, podemos señalar que los Teatinos percibieron un total de 1.550 .057 reales en limosnas, aunque los gastos de la edificación del templo desde 1715 hasta 1761 llegaron a 1.962 .641 reales, sin poder compensar el déficit de 412.584 reales que aún adeudaban en préstamos, materiales y sueldos. Esa cantidad de limosnas se

\footnotetext{
${ }^{4}$ Esta comisión le fue designada por el Marqués de Esquilache.

${ }_{5}$ «En consecuencia de la gracia que V.M. le tiene concedida de hacer construir en ella el retablo de su altar mayor, que hasta ahora no ha podido tener efecto con motivo de estarse construyendo el de la Santa Iglesia de Segovia; solicita que respecto de haberse concluido ya éste se digne V.M. mandar, que se ejecute este [de los Teatinos] conforme está acordado; para lo cual está ya una porción de piedra en las inmediaciones de dicha iglesia», informe de Francisco Sabatini, firmado el 22-09-1775, (A.G.S. Secretaría y Superintendencia de Hacienda, leg. 943).

${ }^{6}$ Francisco Sabatini, ibid., 1993, p. 320, texto de la ficha por Juan Calatrava.

${ }^{7}$ Verdú Ruiz, ob. cit., 1993, p. 422; ob cit., 1998, p. 147.

$A E A$, LXXVII, 2004, 306, pp. 171 a 201
} 
desglosa en las siguientes partidas: Felipe V, 336.000 reales; don Bernardo Rioja y Rojas, 316.092 reales; el Marqués de Mancera, 50.000 reales; el Duque de Alba, 66.000 reales; de legados y limosnas sueltas, 403.223 reales; de los dos Hermanos Padres Araujos, Profesos en la Casa de los Teatinos, 93.340 reales; del Señor Escandón, Arzobispo de Lima, 53.698 reales; del gremio de mercaderes de lienzos, 5.500 reales; de la diputación de los gremios, 6.000 reales; de la venta de casas de la congregación, 163.127 reales; de la Marquesa de Grimaldi, 5.730 reales; de la Duquesa del Infantado, 45.347 reales; de don Antonio Lopedrosa, 6.000 reales. Sirva, en definitiva, este elenco de patrocinadores para conocer un poco más sobre la historia de uno de los templos más representativos del barroco madrileño.

De todo lo expuesto queda constancia de una nueva intervención de Francisco Sabatini en el campo de la retablística, y que aunque es un proyecto no ejecutado constituye una de sus primeras experiencias dentro de ese género en España.

\section{APÉNDICE DOCUMENTAL}

Doc. 1.

1771, mayo, 9. Carta de Francisco Sabatini a Miguel de Múzquiz.

«Ilustrísimo Señor.

Enterado del recurso de la Comunidad de Clérigos Regulares de San Cayetano de Madrid, y del informe y documentos que acompaña el Marqués de Fontanar, relativos al estado de la obra proyectada para la construcción del retablo de la capilla mayor de su iglesia — que todo devuelvo a manos de V.I.— debo decirle que es cierto cuanto se expresa en dichos documentos, y la conducción de la corta porción de piedra a la casa de los mencionados Clérigos Regulares se hizo de cuenta de la consignación del Real Palacio de Madrid, pero haciendo yo presente que las urgencias de la obra de Palacio no podían permitir ni sufrir el peso del gasto de dicho retablo, se suspendió la continuación. Y pidiendo se señalase fondo para su ejecución[,] hasta ahora no tuve ninguna noticia sobre este asunto; quedando en mi poder el diseño aprobado para dicha obra, y para que V.I. quede enterado de su coste y resuelva con el conocimiento correspondiente digo: que dicho retablo de jaspes y bronces dorados, y lo demás que ocurra para ejecutarlo y concluirlo con toda perfección tendrá de costa cerca de ochocientos mil reales de vellón, esto se entiende que se debe trabajar en los talleres del Palacio en donde hay todos los instrumentos necesarios para ejecutar dicha obra, pues a[1] no hacerlo así no bastaría dicha suma para levantar talleres y hacer los intrumentos necesarios, de que tiene muchos el Rey en Palacio que quedan ociosos; del mismo modo y conformidad que se ha ejecutado el altar mayor de la Catedral de la ciudad de Segovia. Que es quanto se me ofrece y parece informar a V.I. cuya vida ruego a Dios Nuestro Señor guarde muchos años.

Aranjuez, 9 de mayo de 1771. Francisco Sabatini.»

(A.G.S. Secretaría y Superintendencia de Hacienda, leg. 943).

Pablo Cano SANZ

Escuela Superior de Conservación y Restauración de Bienes Culturales de Madrid 